\title{
FUTURISTIC PREFERENCES OF ENERGY SOURCES IN THE MILIEU OF ENERGY CRISES: COTTON GROWERS PERSPECTIVE IN PUNJAB, PAKISTAN
}

\author{
Ghazanfar A. Khan*, Muhammad Iftikhar, Babar Shahbaz \\ Institute of Agricultural Extension, Education and Rural Development, University of Agriculture Faisalabad, Pakistan.
}

ARTICLE INF O

\section{Article history}

Received: December 03, 2019

Revised: March 10, 2020

Accepted: April 29, 2020

\section{Keywords}

Energy crises

Energy sources

Cotton growers

\begin{abstract}
A B S T R A C T
Pakistan is one of the prominent countries in the context of growing cotton in the world. Better cotton production paves the way towards thriving textile industry in Pakistan which means a lot to people for many reasons including employment and income generation. However, the energy crises have been putting drastic impacts both on the cotton growers as well as on the textile industry sometime creating a huge supply and demand gap. This study aimed at measuring the futuristic preferred perspectives of the growers in the context of various available energy sources in order to confront energy shortage. Fifty specialized cotton growers were purposively selected from Multan district of the Punjab (Pakistan) in order to collect data and consolidate their future preferences. The collected data were analyzed with the help of Statistical Package for Social Sciences (SPSS). Moreover, the qualitative data were analyzed through content analysis technique. Findings indicated that the hydro and solar energy were in preference with a view of electricity while gas(natural) for the heat purposes. This study urged that for helping the farmers to run the tube well to meet irrigation needs, the electricity should be provided on low rates. On the real grounds, concerted efforts are required to pave the way (especially) for the cotton growers to harness the benefits of solar energy for various pursuits for better agriculture especially for running tube well.
\end{abstract}

*Corresponding Author: Ghazanfar A. Khan

Email: agrigak444@yahoo.com

(C) The Author(s) 2020.

\section{INTRODUCTION}

Farmers are the prime mover for the supply of quality raw cotton to the textile industry. High cotton production with better quality contribute towards thriving textile industry. Pakistan is among the most conspicuous cotton delivering nations in the world. Cotton is contribution is vital with the perspective of Pakistan's economy. However, it had to face a competitive arena with particularly sugarcane crop and international prices. During 2018-19, cotton production with a curtailed cultivated area of 2373 thousand hectares and 9.861 million bales; there appeared a decline of $17.5 \%$ over the last year's production. The negative growth of major crops including cotton production resulted in declined agriculture sector performance (Government of Pakistan, 2019). However, the better cotton production can trigger the way towards progress and prosperity of not only the farmers but also for the textile industry. In Pakistan, the farmers are facing energy crises and impact of load

shedding is drastic and pushing the farmers towards poverty (Ali et al., 2019). Consequently, textile industry is also in crises, on account of low productions of cotton and other allied factors. It looks hard nut to crack to appease such a critical situation. In a situation of quandary and energy crises the perplexity becomes 
multipronged. Getting rid of the dilemma of energy crises become the real way. Pakistan is blessed with options and choices of using diversified energy sources including solar, biomass/waste energy, coal, hydro etc. (Dar et al., 2013). Ahmed et al. (2015) affirmed that textile is undergoing crises and facing various predicaments. In the current situation, energy is the key factor that can play a significant role for thriving production in the industries as well as the economic growth of the country (Ali et al., 2015).

The energy crises are putting multidimensional impacts in various walks of life. The real matter of concern in this perspective is the sound and vivid policy that can smoothen the way towards the sustainable energy supplies to various sectors especially the agricultural and textile industry. It would contribute towards boosting up the economy. In the context of the energy crises, the impediments emerged in the way of economic growth (Government of Pakistan, 2019). The uninterrupted and perpetual supply of energy remained a gigantic task in Pakistan. The study revealed an inverse relationship between the electricity and agriculture sector. Like there is also negative impact of electricity shortage on industrial output (Muhammad, 2015).

In Pakistan, in order to curtail cost of production, improve benefits, balance energy supply, demand and utilization, safe environment, cheap rates and public safety it is deemed quite admissible to exploit existing natural resources. It appeared essential that there should be utilization of natural resources to facilitate the agriculture as well as textile industries of Pakistan. This paper focuses on mainly on the futuristic energy preferences regarding the various energy sources in the milieu of energy crises.

\section{METHODOLOGY}

The population of the study comprised of cotton farmers from the Punjab province. The Multan district was purposively (important for cotton production) selected. Fifty respondents (cotton growers) were selected purposively (who seemed relatively better information source and were eager to give information). An interview schedule (validated and reliable) was developed for the farmers respondents. The data were collected through interview technique from the 50 farmers (cotton growers) from Multan District, Punjab, Pakistan.

A Five-point Likert scale was used for getting the comprehension about the futuristic preferences about energy sources. Both quantitative and qualitative information were collected. The collected data were analyzed with the help of Statistical Package for Social Sciences (SPSS). Moreover, the qualitative data was analyzed through content analysis technique.

\section{RESULTS AND DISCUSSION}

Demographic attributes of the respondents: The socioeconomic characteristics like age, education, land holding, tenure type, farming experience and sources of income are very important in the survey research. In the present study, data regarding the socio- economic characteristics were collected from the respondents.

Table 1. Respondents' Demographic characteristics.

\begin{tabular}{|c|c|c|}
\hline Demographic attributes & $\mathrm{f}$ & $\%$ \\
\hline \multicolumn{3}{|l|}{$x_{0} x_{1}$} \\
\hline Up to 35 years & 26 & 52 \\
\hline$>35-50$ years & 19 & 38 \\
\hline Above 50 years & 5 & 10 \\
\hline \multicolumn{3}{|c|}{ Education } \\
\hline Illiterate & 15 & 30 \\
\hline Primary & 7 & 14 \\
\hline Middle & 6 & 12 \\
\hline Matric & 10 & 20 \\
\hline Intermediate & 7 & 14 \\
\hline Graduation & 5 & 10 \\
\hline \multicolumn{3}{|c|}{ Landholding } \\
\hline Small farmers (Up to 12.5) & 23 & 46 \\
\hline Medium farmers $(>12.5-25)$ & 21 & 42 \\
\hline Large farmers $(>25)$ & 6 & 12 \\
\hline
\end{tabular}




\begin{tabular}{lccc}
\hline & Tenancy status & & \\
\hline Owner & & 35 & 70.0 \\
Owner-cum-tenant & & 5 & 10.0 \\
Tenant & Farming Experience & 20.0 \\
\hline & & 10 & 48 \\
\hline Up to 15 & & 24 & 38 \\
$>15$ to 30 & Source of income & 7 & 14 \\
Above 30 & & 29 & 58.0 \\
\hline Farming only & & 14 & 28.0 \\
Farming+ other business & 7 & 12.0 \\
Farming + job & & 7 \\
\hline
\end{tabular}

Table 1 shows that of the total respondents, more than half (52\%) fell into the age bracket of less than 35 years. One in ten respondents (10\%) was found surpassing 50 years of age. The results show a little more than half of the cotton growers were considerably young farmers. Young energetic chunk and their participation in the farming is important for cotton upscaling in the country. Youth active participation can pave the way towards future thriving agriculture.

Majority (70\%) of the farmers was literate but among the literate respondents one fifth $(20 \%)$ were standing at 10 years of their schooling. The respondents to graduation level are very small in number only $(10 \%)$ of the respondents were graduate. It might be due to that most of the farmers are not interested in getting the higher education. They prefer farming instead of education. They have their own fields and work with their elders, there is much interest for them and they become the permanent part of the farming community but they have more practical knowledge. Approximately one third (30\%) of the respondents were illiterate, they cannot read or write but they are involved in the farming it means they have experienced based indigenous knowledge regarding the cotton growing.

A little less than half (46\%) of the farmers were small farmers. There is also a great number $42 \%$ of the respondents with a little difference were in the category of the medium farmers. Relatively smaller number $12 \%$ of the respondents were in the category of large farmers. The farmers having relatively small piece of land and work as farmers at their field to earn their livelihood. The land is distributed among the young one of the farmers there are small patches of land owned by the cotton growers in the study area due to land division. The prominent feature appeared from the farmers respondents were small farmers followed by medium farmers. It was observed during the data collection that the farmers were having even small piece of land but they were very keen regarding farming practices. Great majority (70\%) of the respondents was the owner. They have their own land who was cultivating their land. Small numbers (10\%) were owner-cum-tenants, and one fifth $(10 \%)$ of the respondents were tenants' cultivators. The conspicuous feature appeared as owner cultivation. A little less than little half (48\%) of the respondents were doing agricultural practices and they were in the category of up to 15 years of farming experience. There were small numbers (14\%) of the respondents who have the more than 30 years of farming experience. Majority (58\%) of the farmers was depending upon the agricultural farming and getting their mean of living from farming. The farmers have their own land and depend on the farming. The respondents revealed the farming as prominent source of income.

\section{Sources of Irrigation}

Proper irrigation is essential for the plants and their production cycle. There are different sources of irrigation that are used by the farmers to meet irrigation needs of the crop. These sources are given in Table 2.

Table 2. Sources of irrigation.

\begin{tabular}{lcc}
\hline Sources of irrigation & $\mathrm{f}$ & $\%$ \\
\hline Canal water only & 6 & 12.0 \\
Tube well only & 18 & 36.0 \\
Canal + tube well & 26 & 52.0 \\
Total & 50 & 100 \\
\hline
\end{tabular}

Table 2 manifests that only $12 \%$ of the respondents were irrigating their land by canal water only. Majority (52\%) of the respondents were using canal and tube well water their fields. Due to shortage of canal water 
most the farmers (36\%) were using tube well water for irrigation purpose. It indicates that farmers have to rely upon energy sources to run the tube well for irrigation water. In this way, they can ensure timely availability of irrigation water if the energy sources are available.

Table 3. perception regarding energy crises $(n=50)$.

\begin{tabular}{lll}
\hline Statement & Yes (f) & $\%$ \\
\hline Facing energy crises & 48 & 96 \\
\hline
\end{tabular}

\section{Perception Regarding Energy Crises}

Table 3 reflects that $96 \%$ of the respondents indicated the dilemma of energy crises with the perspective of Pakistan. The load shedding in the energy crises and consequently agriculture sector is also facing like shortage of irrigation water and other relevant crises. According to the farmers' perceptions they explained that Pakistan has been facing severe energy crises like load shedding which is affecting farmers as they are unable to irrigate their field in time causing late sowing and major impact on the crop growth etc. Ali et al. (2019) had affirmed that in Pakistan the farmers were facing energy crises and impact of load shedding was drastic and pushed the farmers towards poverty circle. There is dire need to address the issue related to energy crises through proper policy for reducing load shedding.

\section{Awareness Regarding Different Energy Sources}

In the modern age different sources of energy can be seen by the farmers. The different sources of energy are categorized as hydro (energy from water), wind (energy from air), biogas, gas (natural)energy from burning of coal and energy from the nuclear sources (Table 4).

Table 4. Awareness regarding various energy sources.

\begin{tabular}{lcc}
\hline Energy Source & Yes (f) & $\%$ \\
\hline Hydro & 50 & 100 \\
Solar & 46 & 92 \\
Wind & 10 & 20 \\
Biogas & 37 & 74 \\
Coal & 50 & 100 \\
Gas & 50 & 100 \\
Nuclear Energy & 6 & 12 \\
\hline
\end{tabular}

Table 4 depicts that all of the respondents $(100 \%)$ were aware of hydro energy, gas, and coal as energy source but with a variation in perceptions. An over whelming majority (92\%) of the respondents were aware of solar as source of energy. The major kind of the hydro energy is electricity. There was also a perception among the respondents about electric current as energy and they know the need of dam for hydropower but knowledge was merely superficial not in-depth in most of the cases. Regarding gas and coal, they were of the view that the major outcome from the both energy source is the heat. From informal discussion, the dominant perception appeared in this context was the use of coal and gas for cooking and domestic purposes. In the context of other energy sources, biogas (74\% awareness) was there but the dimensions of awareness were diversified to look at the scenario. They reflected that they are aware of the use of the solar energy is to operate tube well and also at house level to turn on the solar light and fan etc.

\section{Preferred Future Energy Sources}

The alternative energy sources play a significant role to support the farmer to bring them out of energy crises which they are facing today. The respondents were asked about their preferences regarding different sources which they want to use/ have desire to use it as an energy source. For a sound policy pertinent to energy sources, it seems indispensable and logical to take into consideration the farmers futuristic preferences. To envisage the farmers' perspective regarding the energy sources preferences in futuristic scenario, it was deemed necessary to get the relevant information (Table 5).

Table 5 indicates that hydro energy occupied 1stposition with weighted score 209. Gas was at the 2 nd position with score value 198. Solar energy acquired the 3rd position with weighted score 136 . Biogas, coal, wind and nuclear energy are occupying the 4th, 5th, 6th and 7th position with score value and 74, 33, 24,13 respectively. It may be concluded that most prominent and big and preferred source of energy is no other one but hydro energy. The farmers were having the concept of dam for producing hydroelectric. The hydroelectric seems cheaper source of electricity. Moreover, gas (natural) was preferred due to domestic use. On the other hand, farmer also prefer solar energy as alternative energy source but it is expensive for the farmer to install for particularly agricultural purposes like tube well. The farmers reflected their views that preferred cheapest source is hydro for producing electricity. However, the only problem with it is the high rates of electricity demanded in utility bills. If the hydroelectricity is 
provided with the perspective of its cost it is cheaper and the benefits therefore should be translated as well to the common farmers. The qualitative data revealed that the cotton growers were suffering due to energy crises. They explored during informal discussion that the high prices of electricity and fuel were serious issue for them.

Table 5. Futuristic preference of energy sources by the farmers (cotton growers).

\begin{tabular}{|c|c|c|c|c|c|c|c|c|c|c|c|c|}
\hline \multirow{2}{*}{ Energy sources } & \multicolumn{2}{|c|}{$1=$ Very low } & \multicolumn{2}{|c|}{$2=$ Low } & \multicolumn{2}{|c|}{$3=$ Moderate } & \multicolumn{2}{|c|}{ 4= High } & \multicolumn{2}{|c|}{ 5= Very High } & \multirow{2}{*}{ W.S. } & \multirow{2}{*}{ Ranking } \\
\hline & $\mathrm{f}$ & Score & $\mathrm{f}$ & Score & $\mathrm{f}$ & Score & $f$ & Score & $\mathrm{f}$ & Score & & \\
\hline Hydro & - & - & - & - & 9 & 27 & 23 & 92 & 18 & 90 & 209 & 1 \\
\hline Solar & 1 & 1 & 13 & 26 & 24 & 72 & 3 & 12 & 5 & 25 & 136 & 3 \\
\hline Biogas & 1 & 1 & 6 & 12 & 19 & 57 & 1 & 4 & - & - & 74 & 4 \\
\hline Coal & 2 & 2 & 2 & 4 & 9 & 27 & - & - & - & - & 33 & 5 \\
\hline Gas & - & - & - & - & 4 & 12 & 44 & 176 & 2 & 10 & 198 & 2 \\
\hline Wind & - & - & - & - & 4 & 12 & 3 & 12 & - & - & 24 & 6 \\
\hline Nuclear Energy & - & - & - & - & 3 & 9 & 1 & 4 & - & - & 13 & 7 \\
\hline
\end{tabular}

One of the respondents narrated;

"The price of the diesel is very high and our agricultural commodities are not giving us the required income. We are unable to pay the heavy expenses of the fuel and electricity. Moreover, the load shedding is also creating serious problem for us because we are not getting low cost electricity to operate tube well to irrigate over cotton crop".

Another respondent described that

"Farmers are quite interested in using the solar energy for operating their tube well but due to expensive technology farmer are unable to install the solar panels. Farmers also demand for profuse help on part of government on installation of solar panels for operating tube well.

The respondents also reflected the possible solution to reduce the energy crises so the annual income of them can increase. The said that there should be attention to build dams and try to use alternative of energy like solar. They further suggested that the policy makers should make the policy considering the small farmers. There should be a member from the small farmers to give his opinion while policy making regarding agriculture and to reduce energy crises in the country. Most of the respondents were agree that to use the alternatives of the energy but they were afraid due initial cost of the alternatives of the energy. They were strongly agreed that it was difficult to afford the initial cost of the alternatives of the energy. The respondents were agreed that the dams must be built immediately to reduce the energy crises. During the informal discussion it was concluded that Pakistan is suffering from energy crises due to mismanagement, theft of electricity and gas and improper use of the natural resources. (Ali et al., 2016) in a pertinent research recommended that the motivation should be there for the farmers for using alternate energy sources through subsidies and easy access to credit facilities.

\section{CONCLUSION AND RECOMMENDATIONS}

It is concluded that the majority respondents (cotton growers) under study were young, literate having small landholdings and with farming as a major source of income. Majority of the respondents were using both canal and tube-well water to irrigate their lands. In Pakistan famers have been facing the energy crises. Awareness regarding hydro, solar, gas, coal was there among the respondents. It is also concluded that according to the respondents, hydro energy is the best alternative to be preferred in future. Another alternative is solar energy. These two would be preferred for both agriculture and domestic purpose. Other preferred energy source was gas (natural) for domestic purposes. It is recommended that hydroelectricity should be produced by making dams. However, the practically viable innovative ideas/technologies to harness the hydro energy at small scales should also be considered. The provision of uninterrupted electricity supply should be ensured at low rate. Moreover, in the context of solar energy, there is a dire need to pave the way for more practical and feasible solutions (in terms of availability, accessibility and affordability) pertinent to installation of solar panel for cotton farmers particularly. 


\section{ACKNOWLEDGEMENT}

The paper is a part of report of HEC funded project "Assessment of energy crises and their impact on agrobased industries of Pakistan with special reference to textile industries in Punjab". The financial assistance is highly acknowledged.

\section{REFERENCES}

Ahmed, Y., K. S. J., S. Gul and M. Tariq. 2015. Root causes of the failure of industries in the province of Khyber Pakhtunkhwa, Pakistan. Journal of Applied Environmental and Biological Sciences, 5: 345-56.

Ali, A., B. R. Dil and B. Behera. 2016. Factors influencing farmers' adoption of energy-based water pumps and impacts on crop productivity and household income in Pakistan. Renewable and Sustainable Energy Reviews, 54: 48-57.
Ali, A., D. B. Rahut and M. Imtiaz. 2019. Effects of Pakistan's energy crisis on farm households. Utilities Policy, 59: 100930.

Ali, S., H. Waqas and N. Ahmad. 2015. Analyzing the dynamics of energy consumption, liberalization, financial development, poverty and carbon emissions in Pakistan. Journal of Applied Environmental and Biological Sciences, 5: 166-83.

Dar, M. R., M. Azeem and M. Ramzan. 2013. Impact of energy consumption on Pakistan's economic growth. International Journal of Humanities and Social Sciences, 2: 51-60.

Government of Pakistan. 2019. Economic survey of Pakistan2018-2019. Economic Advisor's Wing, Ministry of. Finance, Islamabad.

Muhammad, S. 2015. Measuring economic cost of electricity shortage: current challenges and future prospects in Pakistan. MPRA Paper 67164.

Publisher's note: EScience Press remains neutral with regard to jurisdictional claims in published maps and institutional affiliations.

Open Access This article is licensed under a Creative Commons Attribution 4.0 International License, which permits use, sharing, adaptation, distribution and reproduction in any medium or format, as long as you give appropriate credit to the original author(s) and the source, provide a link to the Creative Commons license and indicate if changes were made. The images or other third-party material in this article are included in the article's Creative Commons license, unless indicated otherwise in a credit line to the material. If material is not included in the article's Creative Commons license and your intended use is not permitted by statutory regulation or exceeds the permitted use, you will need to obtain permission directly from the copyright holder. To view a copy of this license, visit http://creativecommons.org/licenses/by/4.0/. 